\title{
Curculigoside attenuates myocardial ischemia-reperfusion injury by inhibiting the opening of the mitochondrial permeability transition pore
}

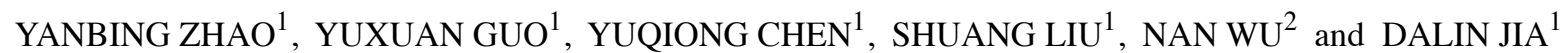 \\ Departments of ${ }^{1}$ Cardiology and ${ }^{2}$ Central Laboratory, The First Affiliated Hospital of \\ China Medical University, Shenyang, Liaoning 110001, P.R. China \\ Received September 12, 2019; Accepted February 3, 2020
}

DOI: $10.3892 /$ ijmm.2020.4513

\begin{abstract}
The aim of the present study was to determine whether curculigoside protects against myocardial ischemia-reperfusion injury (MIRI) and to investigate the underlying mechanisms. An in vitro model of hypoxia/reoxygenation $(\mathrm{H} / \mathrm{R})$ was established by culturing $\mathrm{H} 9 \mathrm{c} 2$ cells under hypoxic conditions for $12 \mathrm{~h}$, followed by reoxygenation for 1 h. Cell Counting kit-8 and lactate dehydrogenase (LDH) assays were subsequently used to examine cell viability and the degree of cell injury. In addition, isolated rat hearts were subjected to $30 \mathrm{~min}$ of ischemia followed by $1 \mathrm{~h}$ of reperfusion to establish a MIRI model. Triphenyltetrazolium chloride (TTC) staining was performed to measure the infarct size. Furthermore, TUNEL staining and flow cytometry were employed to evaluate cell apoptosis. The opening of the mitochondrial permeability transition pore (MPTP) and changes in the mitochondrial membrane potential $(\Delta \Psi \mathrm{m})$ were assessed. Reverse transcription-quantitative PCR and western blot analysis were performed to investigate the expression levels of mitochondrial apoptosis-related proteins. Curculigoside pre-treatment significantly improved cell viability, decreased cell apoptosis and LDH activity, and reduced the infarct size and myocardial apoptosis in vitro and ex vivo, respectively. Moreover, curculigoside markedly inhibited MPTP opening and preserved the $\Delta \Psi \mathrm{m}$. In addition, curculigoside significantly decreased the expression of cytochrome $c$, apoptotic protease
\end{abstract}

Correspondence to: Dr Dalin Jia, Department of Cardiology, The First Affiliated Hospital of China Medical University, 155 North of Nanjing Street, Shenyang, Liaoning 110001, P.R. China

E-mail: jd12001@126.com

Dr Nan Wu, Department of Central Laboratory, The First Affiliated Hospital of China Medical University, 155 North of Nanjing Street, Shenyang, Liaoning 110001, P.R. China

E-mail: imwunan@163.com

Key words: curculigoside, myocardial ischemia-reperfusion injury, mitochondrial permeability transition pore, mitochondria-mediated apoptosis activating factor-1, cleaved caspase-9 and cleaved caspase-3. Notably, atractyloside, a known MPTP opener, abrogated the protective effects of curculigoside. On the whole, the present study demonstrated that curculigoside protected against MIRI, potentially by decreasing the levels of mitochondria-mediated apoptosis via the inhibition of MPTP opening. Therefore, the results obtained in the present study may provide the theoretical basis for the future clinical application of curculigoside.

\section{Introduction}

Acute myocardial infarction (AMI) is a major cause of mortality worldwide and the incidence of AMI has increased in China in recent years. Revascularization to restore blood flow is currently the most effective treatment for AMI (1). However, while early reperfusion is effective in decreasing mortality, the perfusion of previously ischemic myocardial tissue results in a second wave of injury, which is referred to as myocardial ischemia-reperfusion injury (MIRI) $(2,3)$. MIRI may lead to severe adverse events, including acute left ventricular failure and malignant arrhythmia (4). Therefore, preventing MIRI in the early stages of AMI may improve patient prognosis.

The mitochondrial permeability transition pore (MPTP), which is located in the inner membrane, plays an important role in apoptosis (5). Following ischemia, reperfusion may result in the generation of reactive oxygen species and $\mathrm{Ca}^{2+}$ influx, which may lead to the opening of the MPTP $(6,7)$. The opening of the MPTP, which is known as the mitochondrial permeability transition, decreases the inner mitochondrial membrane potential $(\Delta \Psi \mathrm{m})$. It also leads to the release of cytochrome $c$ into the cytoplasm and activates caspase, resulting in mitochondrial dysfunction and swelling, eventually leading to apoptosis (8-11). Previous studies have demonstrated that the inhibition of the opening of the MPTP with an inhibitor, such as cyclosporin A, may alleviate MIRI $(12,13)$, while promoting MPTP opening, with for example, atractyloside, may aggravate MIRI (14). Therefore, the MPTP may serve as an important target for modulating MIRI.

Certain natural compounds are known to exert pharmacological actions and are generally well-tolerated by the human body. Curculigoside, extracted from Curculigo orchioides Gaertn, is a phenolic glycoside antioxidant that 
exerts anti-inflammatory and antitumor effects (15-17). Curculigoside has been demonstrated to inhibit $\mathrm{H}_{2} \mathrm{O}_{2}$-induced oxidative stress in human umbilical vein endothelial cells (18). Furthermore, several studies have reported that curculigoside attenuates experimental cerebral ischemia injury in vitro and ex vivo (19-21). However, whether curculigoside exerts a cardioprotective effect following I/R injury remains unclear.

The aim of the present study was to determine whether curculigoside exerts cardioprotective effects following I/R or $\mathrm{H} / \mathrm{R}$ injury in vitro and ex vivo and to investigate whether the underlying mechanisms involve the inhibition of MPTP opening.

\section{Materials and methods}

Drugs. Curculigoside (CAS no. 85643-19-2; formula, $\mathrm{C}_{22} \mathrm{H}_{26} \mathrm{O}_{11}$; the chemical structure of curculigoside can be found at: http://www.chemfaces.com/natural/Curculigoside-CFN97419. html) and atractyloside were purchased from ChemFaces ${ }^{\circledR}$ and Nantong Feiyu Biological Technology Co. Ltd., respectively. Both drugs were dissolved in $1 \%$ dimethyl sulfoxide (DMSO; Solarbio Science \& Technology Co.) and stored at $-20^{\circ} \mathrm{C}$ until further use.

Cell culture. H9c2 rat cardiomyocytes were purchased from the Cell Bank of the Chinese Academy of Sciences. Cells were cultured in Dulbecco's modified Eagle's medium (DMEM) supplemented with $10 \%$ fetal bovine serum and $1 \%$ penicillin/streptomycin at $37^{\circ} \mathrm{C}$ in a humidified atmosphere containing $5 \% \mathrm{CO}_{2}$.

Induction of the H/R model in vitro. Upon reaching 80-90\% confluence, the $\mathrm{H} 9 \mathrm{c} 2$ cells were pre-treated with curculigoside $(5,10$ and $15 \mu \mathrm{M})$ or the equivalent volume of $1 \%$ DMSO for $8 \mathrm{~h}$. The spent DMEM was replaced with glucose- and FBS-free Earle's medium in all groups, except for the control group. Cells were subsequently incubated in a tri-gas chamber containing $95 \%(\mathrm{v} / \mathrm{v}) \mathrm{N}_{2}, 5 \%(\mathrm{v} / \mathrm{v}) \mathrm{CO}_{2}$ and $5 \% \mathrm{O}_{2}$ at $37^{\circ} \mathrm{C}$ for $12 \mathrm{~h}$ to induce hypoxia. Earle's medium was replaced with DMEM supplemented with $10 \%$ FBS and the cells were incubated at $37^{\circ} \mathrm{C}$ and $5 \% \mathrm{CO}_{2}$ for $1 \mathrm{~h}$ to allow reoxygenation.

Cell experiment protocol. $\mathrm{H} 9 \mathrm{c} 2$ cells were divided into 6 groups as follows: i) The control group; ii) the hypoxia/reoxygenation group (H/R); iii) the vehicle group; iv) the $5 \mu \mathrm{M}$ curculigoside-treated group; v) the $10 \mu \mathrm{M}$ curculigoside-treated group; and vi) the $15 \mu \mathrm{M}$ curculigoside-treated group. Based on the results obtained, curculigoside was used at a concentration of $10 \mu \mathrm{M}$ in subsequent experiments. H9c2 cells were subsequently divided into 5 groups as follows: i) The control group; ii) the H/R group; iii) the vehicle group; iv) the $10 \mu \mathrm{M}$ curculigoside-treated group; v) the combined treatment group (10 $\mu \mathrm{M}$ curculigoside and $20 \mu \mathrm{M}$ atractyloside). The curculigoside-treated and combined treatment groups were treated with curculigoside and curculigoside and atractyloside, respectively, for $8 \mathrm{~h}$ prior to $\mathrm{H} / \mathrm{R}$.

Assessment of cell proliferation. The proliferation of the H9c2 cells was assessed using a Cell Counting kit-8 (BD Biosciences) assay, according to the manufacturer's protocol.
The H9c2 cells $\left(3 \times 10^{3}\right.$ cells/well) were cultured in 96 -well plates. Following treatment, $10 \mu \mathrm{l}$ CCK- 8 solution were added to each well and incubated for $1 \mathrm{~h}$ at $37^{\circ} \mathrm{C}$ in a $5 \% \mathrm{CO}_{2}$ incubator. The optical density was measured at a wavelength of $490 \mathrm{~nm}$ using a microplate reader (Biotek Instruments, Inc.).

Assessment of lactate dehydrogenase (LDH) activity. $\mathrm{LDH}$ activity was assessed to evaluate the cytoprotective effects of curculigoside. An LDH assay (Nanjing Jiancheng Bioengineering Institute) was performed according to the manufacturer's instructions. The optical density was measured at a wavelength of $450 \mathrm{~nm}$ using a microplate reader (Biotek Instruments, Inc.) and was used to calculate the concentration of LDH.

Assessment of H9c2 cell apoptosis. The apoptotic rate of the $\mathrm{H} 9 \mathrm{c} 2$ cells was evaluated by flow cytometry using an Annexin V-fluorescein isothiocyanate (FITC)/propidium iodide (PI) kit (BD Biosciences). Cells in 6-well plates were trypsinized and washed twice in ice-cold PBS. Cells were suspended in binding buffer and $5 \mu \mathrm{l}$ Annexin V-FITC and $5 \mu \mathrm{l}$ PI were added to each sample. The cells were incubated at room temperature in the dark for $15 \mathrm{~min}$ and analyzed using a flow cytometer (BD Biosciences).

Assessment of $\Delta \Psi_{m}$. The change in $\Delta \Psi_{\mathrm{m}}$ was measured by rhodamine 123 staining following the manufacturer's protocol (Beyotime Institute of Biotechnology). Cell apoptosis leads to a decrease in $\Delta \Psi_{\mathrm{m}}$ and a reduction in the fluorescence intensity in cells. The H9c2 cells were incubated with rhodamine 123 for $30 \mathrm{~min}$ at $37^{\circ} \mathrm{C}$ in the dark. Cells were visualized by fluorescence microscopy (IX73, Olympus) and the staining was analyzed using Image-Pro software.

Assessment of MPTP opening. MPTP opening was determined using the $\mathrm{CaCl}_{2}$-induced method (22). Mitochondria were isolated from the $\mathrm{H} 9 \mathrm{c} 2$ cells using the Mitochondrial Extract kit (BestBio Co.), according to the manufacturer's instructions. The sensitivity of MPTP opening to $\mathrm{Ca}^{2+}$ was determined using the Purified Mitochondrial Membrane Pore Channel Colorimetric Assay kit (Shanghai Genmed Pharmaceutical Technology Co., Ltd.), according to the manufacturer's protocol.

Animals and animal care. Male Wistar rats (age, 8 weeks; weight, $300 \pm 30 \mathrm{~g}$ ) were purchased from Liaoning Changsheng Biotechnology Co. and housed in environmentally-controlled conditions (temperature, $22 \pm 2^{\circ} \mathrm{C}$; relative humidity, $60 \pm 5 \%$; 12-h light/dark cycles). All rats were allowed to acclimatize to their environment prior to the experiments and fed a standard diet. Food and bedding were changed for the rats, and the health of the animals was monitored every other day. The present study was approved by the Ethics Committee of China Medical University and procedures for animals handling and care adhered to the Guide for the Care and Use of Laboratory Animals (23).

Induction of the ischemia-reperfusion group (I/R) model. Krebs-Henseleit (K-H) buffer $(0.15 \mathrm{~mol} / 1 \mathrm{NaCl}, 0.006 \mathrm{~mol} / 1$ $\mathrm{KCl}, 0.002 \mathrm{~mol} / 1 \mathrm{CaCl}_{2}, 0.002 \mathrm{~mol} / 1 \mathrm{NaHCO}_{3}$ and $0.011 \mathrm{~mol} / \mathrm{l}$ 
glucose) was prepared and the $\mathrm{pH}$ was adjusted to 7.35-7.45 by the addition of $\mathrm{NaOH}$. The rats were anesthetized by an intraperitoneal injection of $30 \mathrm{mg} / \mathrm{kg}$ pentobarbital sodium. An incision was made into the thoracic cavity and the heart was rapidly removed and placed in ice-cold heparinized K-H buffer with continuous oxygenation (oxygen flow rate, 3 1/min). The heart connective tissue was resected to expose the aorta, which was subsequently connected to a Langendorff system. The isolated hearts were retrogradely perfused with $\mathrm{K}-\mathrm{H}$ buffer containing $95 \% \mathrm{O}_{2}$ and $5 \% \mathrm{CO}_{2}$ for $15 \mathrm{~min}$ at $37^{\circ} \mathrm{C}$ and at a constant pressure of $76 \mathrm{mmHg}$. Rat hearts were subjected to global ischemia for $30 \mathrm{~min}$, followed by $60 \mathrm{~min}$ of reperfusion to generate the MIRI model as described in a previous study by the authors (24). All rats used in this study (total, 165 rats) were subjected to euthanasia. As for the details of euthanasia, each of the rats was anesthetized in an isolated room individually by intraperitoneal injection of pentobarbital sodium at a dose of $30 \mathrm{mg} / \mathrm{kg}$. After confirming that the rat was completely anesthetized and unconscious by determining whether the rats exhibited nerve reflexes or not, the chest of the rat was opened, the aorta was disconnected and the heart was rapidly isolated to induce the permanent cessation of circulation. The experiment described herein is an acute, non-survival experiment. Euthanasia was achieved by exsanguination during the harvesting of the heart as previously described (25).

Animal experiment protocol. The rats were randomly divided into 6 groups ( $\mathrm{n}=15$ rats per group) as follows: i) The control group; ii) the I/R group; iii) the vehicle group; iv) the $5 \mathrm{mg} / \mathrm{kg}$ curculigoside-treated group; v) the $10 \mathrm{mg} / \mathrm{kg}$ curculigoside-treated group; and vi) the $15 \mathrm{mg} / \mathrm{kg}$ curculigoside-treated group. Prior to isolation of the hearts, the rats in the curculigoside-treated groups received a daily intraperitoneal injection of curculigoside for 7 days. The animals in the vehicle group received the equivalent volume of $1 \%$ DMSO.

Based on the results obtained, $10 \mathrm{mg} / \mathrm{kg}$ curculigoside was selected for further experimentation. The rats were randomly divided into 5 groups ( $\mathrm{n}=15$ rats per group) as follows: i) The control group; ii) the I/R group; iii) the vehicle group; iv) the $10 \mathrm{mg} / \mathrm{kg}$ curculigoside-treated group; v) the combined treatment group $(10 \mathrm{mg} / \mathrm{kg}$ curculigoside and $5 \mathrm{mg} / \mathrm{kg}$ atractyloside). Similar to the curculigoside-treated group, the animals in the combined treatment group received a daily intraperitoneal injection of curculigoside and atractyloside for 7 days prior to surgery.

Assessment of infarct size. Triphenyltetrazolium chloride (TTC) staining was performed to quantify the infarct size in myocardial tissues. The heart was removed and the left ventricular tissue was frozen at $-70^{\circ} \mathrm{C}$ and subsequently cut into 2-mm-thick sections. The sections were incubated with $1 \%$ TTC (Solarbio Science \& Technology Co.) at $37^{\circ} \mathrm{C}$ for $30 \mathrm{~min}$ at $37^{\circ} \mathrm{C}$ in the dark. Images of the staining were acquired using a digital camera (EOS 90D, Canon) and the staining was quantified by ImageJ $2 x$ software.

Assessment of myocardial morphological changes. Hearts were removed from the Langendorff system after $1 \mathrm{~h}$ of reperfusion and fixed in $4 \%$ paraformaldehyde overnight at $4^{\circ} \mathrm{C}$. Following dehydration with ethanol, the left ventricular tissue
Table I. Primer sequences used for quantitative PCR.

Primers Primer sequences (5'-3')

Cytochrome $c$

Cytochrome $c$

APAF1

APAF1

Caspase-9

Caspase-9

Caspase-3

Caspase-3

Bax

Bax

Bcl-2

Bcl-2 Forward: AGGGTGTCGCCTCAAACCTA Reverse: ACTGAAGCACGGGTGAGTCT Forward: CAAGGACACAGACGGTGGAA Reverse: TGAATCGCACTGACCAGCTT Forward: CAGGTGGAGGTCAGGTGTGA Reverse: TCCGTGAGAGAGGATGACCA Forward: CCATCCTTCAGTGGTGGACA Reverse: TTGAGGCTGCTGCATAATCG Forward: GGCGATGAACTGGACAACAA Reverse: CAGTTGAAGTTGCCGTCTGC Forward: CACGGTGGTGGAGGAACTCT Reverse: TCCACAGAGCGATGTTGTCC

was embedded in paraffin and cut into $5-\mu \mathrm{m}$-sections using a rotary microtome. Following dewaxing and rehydration, the sections were immersed in hematoxylin solution for $5 \mathrm{~min}$, $1 \%$ hydrochloric acid alcohol for $3 \mathrm{sec}$, and eosin solution for $3 \mathrm{~min}$ at room temperature for staining. Myocardial morphological characteristics were subsequently observed using a light microscope (CX23, Olympus).

Assessment of myocardial apoptosis. Terminal deoxynucleotidyl-transferase-mediated dUTP nick-end labeling (TUNEL) staining was performed to assess myocardial apoptosis using the In Situ Cell Death Detection kit (Roche Diagnostics), according to the manufacturer's instructions. TUNEL-positive cells were stained dark grey and were visible under a light microscope (CX23, Olympus).

Assessment of protein expression. Total protein was extracted from myocardial tissue and $\mathrm{H} 9 \mathrm{c} 2$ cells using radioimmunoprecipitation assay buffer and protease inhibitors. Total protein was quantified using a bicinchoninic acid assay and $30 \mu \mathrm{g}$ protein/lane was separated via SDS-PAGE on $10 \%$ gels. The separated proteins were subsequently transferred onto polyvinylidene difluoride membranes and blocked for $1 \mathrm{~h}$ at room temperature with 5\% skim milk dissolved in TBST. The membranes were then incubated with primary antibodies against B-cell lymphoma 2 (Bcl-2; 1:500; Wan Biotechnology; cat. no. WL01556), Bcl-2-associated X protein (Bax; 1:500; Wan Biotechnology; cat. no. WL01637), apoptotic protease activating factor-1 (APAF-1; 1:1,000; Proteintech; cat. no. 21093-1-AP), cytochrome $c(1: 1,000$; Proteintech; cat. no. 66264-1-Ig), cleaved caspase-9 (1:500; Wan Biotechnology; cat. no. 66264-1-Ig), cleaved caspase-3 (1:500; Wan Biotechnology; cat. no. WL01992), $\beta$-actin (1:500; Wan Biotechnology; cat. no. WL01372) overnight at $4^{\circ} \mathrm{C}$. Following incubation with the primary antibodies, the membranes were incubated with horseradish peroxidase-labeled anti-mouse and anti-rabbit secondary antibodies (both 1:4,000; EarthOx Life Sciences; cat. no. E030110-02 and E030120-02) for $0.5 \mathrm{~h}$ at room temperature. Protein bands were visualized using enhanced chemiluminescence substrates. Protein expression was quantified using ImageJ software (version 1.51). 

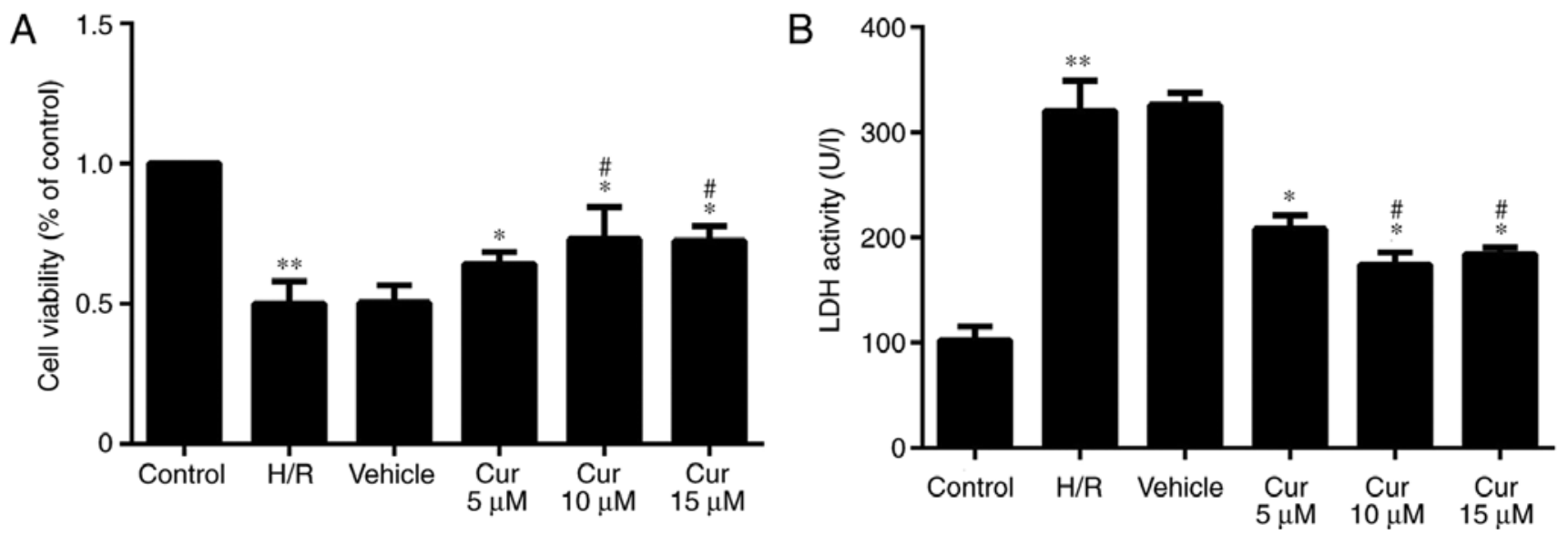

Figure 1. Effect of curculigoside on $\mathrm{H} / \mathrm{R}$ injury in vitro. (A) $\mathrm{H} 9 \mathrm{c} 2$ cell proliferation was measured using the Cell Counting kit-8 assay. (B) LDH activity was determined by a LDH assay. ${ }^{* *} \mathrm{P}<0.05$ vs. the control group, ${ }^{\mathrm{H}} \mathrm{P}<0.05$ vs. the $\mathrm{H} / \mathrm{R}$ group, ${ }^{, \mathrm{P}}<0.05$ vs. the $5 \mu \mathrm{M}$ curculigoside-treated group. $\mathrm{H} / \mathrm{R}$, hypoxia/reoxygenation; LDH, lactate dehydrogenase; Cur, curculigoside.

Assessment of mRNA expression. Total RNA was extracted from myocardial tissue and H9C2 cells using TRIzol ${ }^{\circledR}$ reagent (Solarbio Science \& Technology Co.), according to the manufacturer's protocol. The concentration and the purity of the RNA samples were analyzed using the Nanodrop 2000 System (Thermo Fisher Scientific, Inc.). Total RNA was reverse transcribed into cDNA using the PrimeScript RT reagent kit (Takara Bio), according to the manufacturer's protocol. The following temperature protocol was used: $37^{\circ} \mathrm{C}$ for $15 \mathrm{~min}$, $85^{\circ} \mathrm{C}$ for $5 \mathrm{sec}$ and cooling down to $4^{\circ} \mathrm{C}$. qPCR was subsequently performed using the SYBR Premix Ex Taq II (Takara Bio), according to the manufacturer's instructions. The primer pairs used for qPCR were designed by Biotechnology Co., Ltd. and are presented in Table I. The following thermocycling conditions were used: i) Step $1,5 \mathrm{~min}$ at $95^{\circ} \mathrm{C}$; ii) step 2 , 8 cycles at $95^{\circ} \mathrm{C}$ for $30 \mathrm{sec}$, at $60^{\circ} \mathrm{C}$ for $45 \mathrm{sec}$, at $72^{\circ} \mathrm{C}$ for $20 \mathrm{sec}$; iii) step 3,35 cycles at $95^{\circ} \mathrm{C}$ for $30 \mathrm{sec}$, at $56^{\circ} \mathrm{C}$ for $45 \mathrm{sec}$, at $72^{\circ} \mathrm{C}$ for $20 \mathrm{sec}$; and iv) step $4,1 \mathrm{~min}$ at $95^{\circ} \mathrm{C}, 30 \mathrm{sec}$ at $55^{\circ} \mathrm{C}, 30 \mathrm{sec}$ at $95^{\circ} \mathrm{C}$. GAPDH was used as the internal reference gene. Target gene mRNA levels were quantified using the $2^{-\Delta \Delta \mathrm{Cq}}$ method (26).

Statistical analysis. To ensure the consistency and repeatability of the results, individual experiments were performed in triplicate. The experimental results are presented as the means \pm standard deviation. One-way analysis of variance followed by Tukey's multiple comparison test was used to compare the groups. $\mathrm{P}<0.05$ was considered to indicate a statistically significant difference. All data were analyzed using SPSS software (version 20.0; IBM Corp.).

\section{Results}

Curculigoside inhibits $H / R$ injury in $H 9 c 2$ cells in vitro. Following H/R injury, the proliferation of the H9c2 cells was significantly decreased. Curculigoside pre-treatment significantly increased cell proliferation following $H / R$ injury. The protective effects of 10 and $15 \mu \mathrm{M}$ curculigoside on cell viability were significantly more prominent compared with those of $5 \mu \mathrm{M}$ curculigoside. No significant differences were observed between the 10 and $15 \mu \mathrm{M}$ curculigoside groups (Fig. 1A). The results of LDH assay revealed that LDH activity in the $H / R$ group was significantly increased compared with that in the control group. The activity of LDH was significantly decreased following curculigoside pre-treatment. LDH activity in the 10 and $15 \mu \mathrm{M}$ curculigoside-treated groups was significantly lower compared with that in the $5 \mu \mathrm{M}$ curculigoside-treated group. However, there was no significant difference in LDH activity between the 10 and $15 \mu \mathrm{M}$ curculigoside-treated groups (Fig. 1B). Therefore, the concentration of $10 \mu \mathrm{M}$ curculigoside was selected for use in subsequent experiments.

Curculigoside decreases $H 9 c 2$ cell apoptosis and inhibits the decrease in $\Delta \Psi m$. Following rhodamine 123 staining, the florescence intensity was significantly increased in the H9c2 cells in the curculigoside-treated group compared with the $\mathrm{H} / \mathrm{R}$ group, demonstrating that curculigoside pre-treatment effectively prevented the decrease in $\Delta \Psi_{\mathrm{m}}$ and maintained a high $\Delta \Psi \mathrm{m}$. On the other hand, the $\mathrm{H} / \mathrm{R}$ group exhibited a loss in $\Delta \Psi_{\mathrm{m}}$ (Fig. 2A). Flow cytometric analysis revealed that following $\mathrm{H} / \mathrm{R}$ injury, apoptosis was significantly increased in the untreated H9c2 cells compared with the control group. Furthermore, pre-treatment with curculigoside significantly inhibited H9c2 cell apoptosis following H/R compared with the H/R group (Fig. 2B).

Curculigoside inhibits mitochondrial-mediated apoptosis. RT-qPCR analysis revealed that $H / R$ injury significantly upregulated the mRNA expression of cytochrome $c$, APAF-1, caspase- 9 and caspase- 3 in the $\mathrm{H} 9 \mathrm{c} 2$ cells compared with the control group in vitro. Curculigoside pre-treatment significantly attenuated the increased mRNA expression of cytochrome $c$, APAF-1, caspase- 9 and caspase- 3 in vitro (Fig. 3A). Consistent with the changes observed in mRNA expression, western blot analysis revealed that the protein expression of the aforementioned proteins in the H/R group was significantly increased compared with the control group and treatment with curculigoside prior to H/R injury significantly attenuated these increased expression levels (Fig. 3B).

Curculigoside inhibits the opening of the MPTP. The results revealed that the sensitivity of MPTP opening to $\mathrm{Ca}^{2+}$ was 


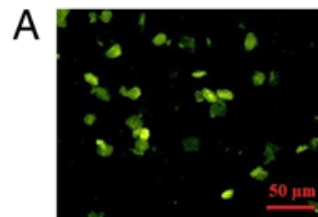

Control

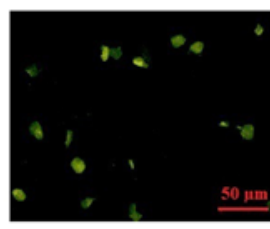

Cur

B
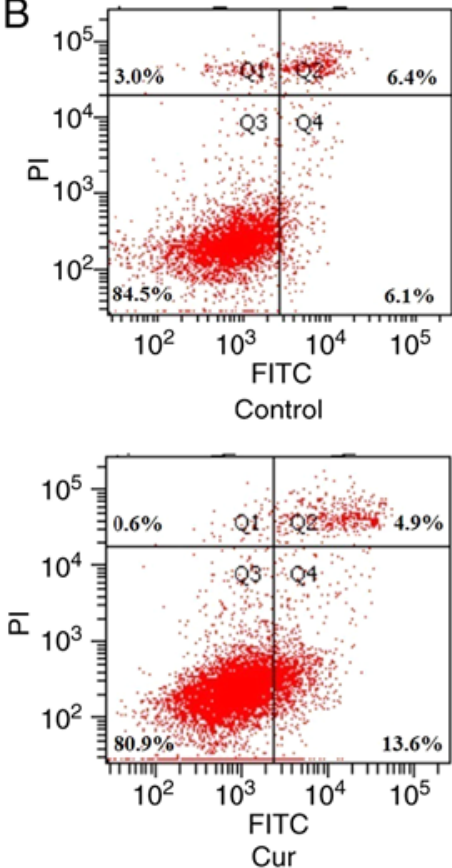

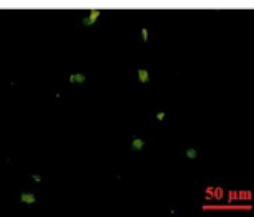

$\mathrm{H} / \mathrm{R}$

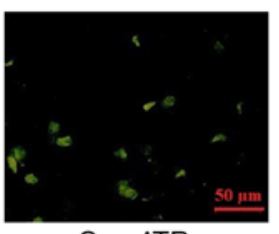

Cur+ATR

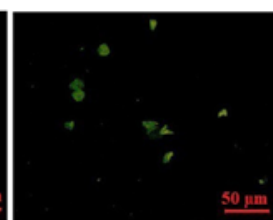

Vehicle
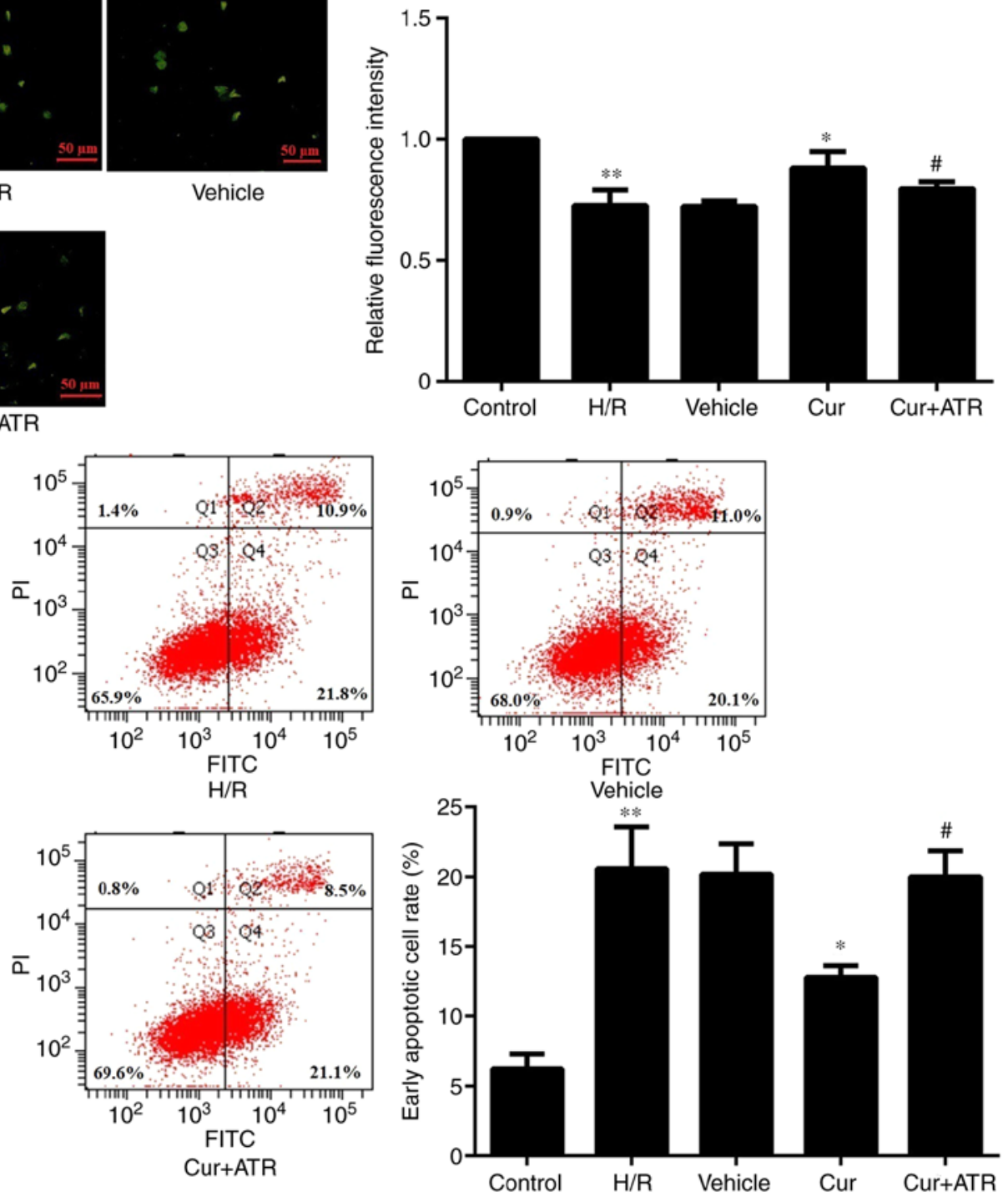

Figure 2. Curculigoside inhibits $H 9 \mathrm{c} 2$ cell apoptosis and preserves $\Delta \Psi \mathrm{m}$. (A) $\mathrm{H} 9 \mathrm{c} 2$ cell apoptosis was assessed by flow cytometry. (B) The change in $\Delta \Psi \mathrm{m}$ was measured by rhodamine 123 staining. ${ }^{* *} \mathrm{P}<0.05$ vs. the control group ${ }^{*} \mathrm{P}<0.05$ vs. the $\mathrm{H} / \mathrm{R}$ group, ${ }^{\#} \mathrm{P}<0.05$ vs. the curculigoside-treated group. $\Delta \Psi \mathrm{m}$, mitochondrial membrane potential; H/R, hypoxia/reoxygenation; Cur, curculigoside; ATR, atractyloside.

significantly increased in the $\mathrm{H} / \mathrm{R}$ group as compared with the control group, meanwhile, pre-treatment with curculigoside significantly decreased the sensitivity of MPTP opening to $\mathrm{Ca}^{2+}$ compared with the H/R group, indicating that curculigoside inhibited MPTP opening following H/R injury (Fig. 4).

Curculigoside regulates the expression of Bax and Bcl-2 at the gene and protein levels. RT-qPCR analysis indicated that $\mathrm{H} / \mathrm{R}$ injury significantly upregulated the mRNA expression of Bax, downregulated Bcl-2 expression and decreased the ratio of Bcl-2/Bax compared with the control group. Curculigoside treatment significantly attenuated the changes in mRNA expression and increased the ratio of Bcl-2/Bax (Fig. 5A). Similarly, western blot analysis revealed that the protein expression levels of Bax and Bcl-2 were significantly increased and decreased, respectively, in the H/R group compared with the control group. Pre-treatment with curculigoside significantly attenuated the increased protein expression of Bax, the decreased protein expression of $\mathrm{Bcl}-2$ and the decreased ratio of Bcl-2/Bax (Fig. 5B).
Curculigoside attenuates I/R-induced myocardial injury ex vivo. In order to examine the potential cardioprotective effects of curculigoside, rat hearts were isolated and subjected to I/R with or without pre-treatment with 5,10 and $15 \mathrm{mg} / \mathrm{kg}$ curculigoside. Curculigoside pre-treatment significantly decreased the infarct size compared with the I/R group. Furthermore, the infarct size was decreased in the 10 and $15 \mathrm{mg} / \mathrm{kg}$ curculigoside-treated groups compared with the $5 \mathrm{mg} / \mathrm{kg}$ curculigoside-treated group. However, there was no statistically significant difference between the infarct sizes in the 10 and $15 \mathrm{mg} / \mathrm{kg}$ curculigoside-treated groups (Fig. 6A). $\mathrm{H} \& \mathrm{E}$ staining revealed that the myocardial fibers in the control group were of a normal size and highly aligned. In the I/R group, the myocardial fibers were loosely and irregularly arranged and inflammatory cell infiltration and myocardial cell edema were observed. However, these pathological changes were less pronounced in the curculigoside-treated groups, particularly in the $10 \mathrm{mg} / \mathrm{kg}$ curculigoside-treated group (Fig. 6B). Accordingly, $10 \mathrm{mg} / \mathrm{kg}$ curculigoside was selected as the optimal dose and was used for subsequent experimentation. 


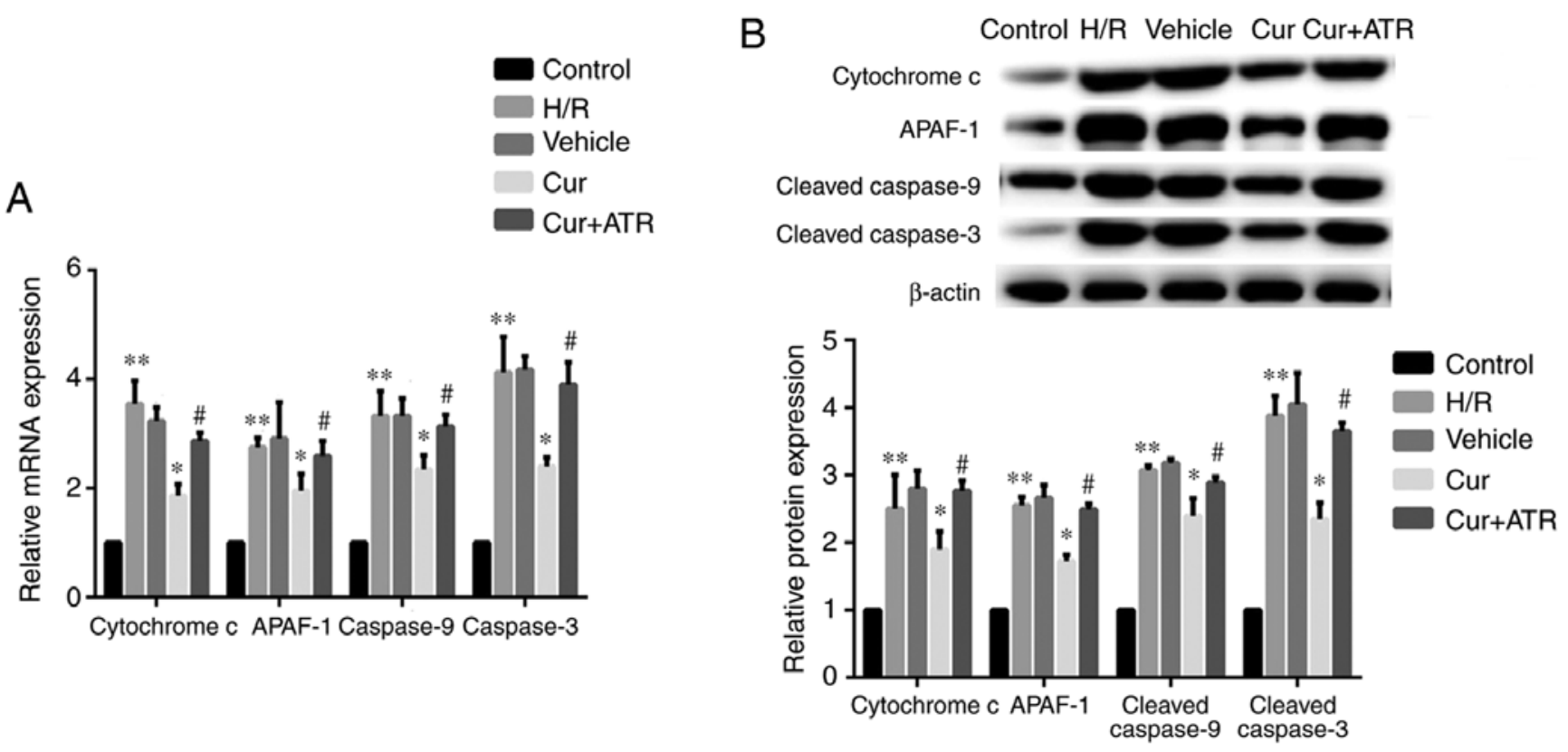

Figure 3. Curculigoside reduces the expression of cytochrome $c$, APAF-1, caspase-9 and caspase- 3 at the gene and protein levels in vitro. (A) The mRNA expression of cytochrome $c$, APAF-1, caspase-9 and caspase-3 was determined by RT-qPCR. (B) The protein expression of cytochrome $c$, APAF-1, cleaved caspase-9 and cleaved caspase- 3 was evaluated by western blot analysis. ${ }^{*} \mathrm{P}<0.05$ vs. the control group, ${ }^{*} \mathrm{P}<0.05$ vs. the $\mathrm{H} / \mathrm{R}$ group, ${ }^{*} \mathrm{P}<0.05$ vs. the curculigoside-treated group. APAF-1, apoptotic protease activating factor-1; H/R, hypoxia/re-oxygenation; Cur, curculigoside; ATR, atractyloside.

A

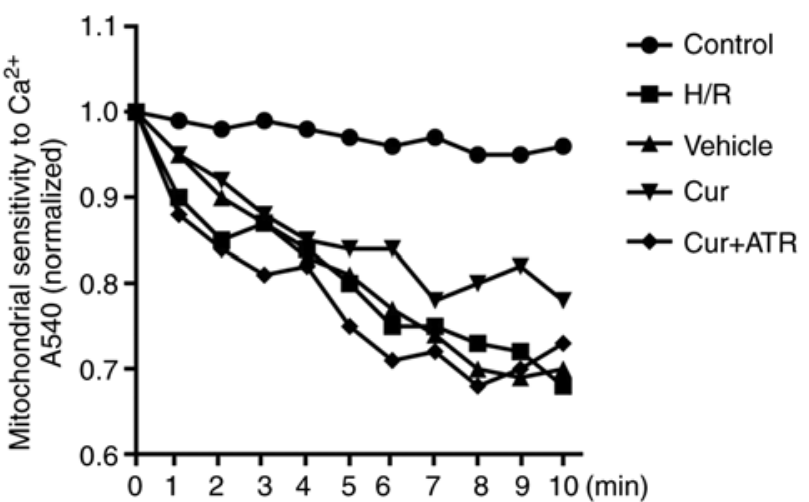

B

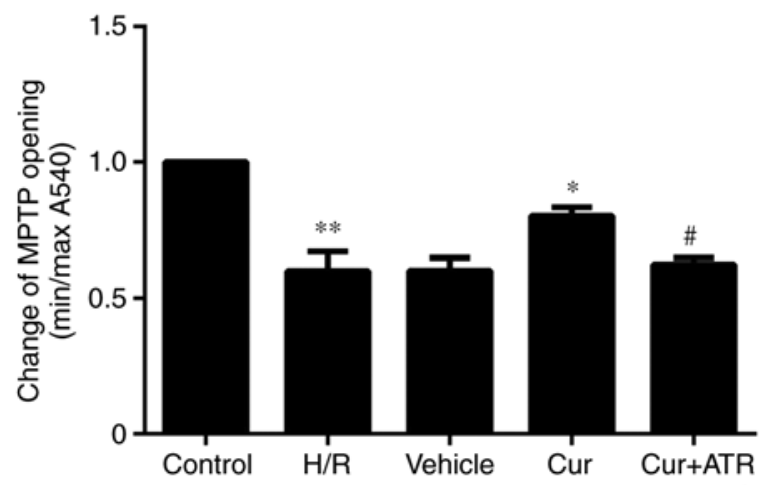

Figure 4. Effect of curculigoside on MPTP opening. (A) MPTP opening was induced by $\mathrm{CaCl}_{2}$. (B) Statistical analysis for MPTP opening. Minimum optical density (min OD) represents the OD value recorded at the end of the experiment (10 min); maximum optical density (max OD) represents the OD value recorded at the onset of the experiment $(0 \mathrm{~min})$. Min/max OD is negatively associated with the extent of MPTP opening. ${ }^{* *} \mathrm{P}<0.05$ vs. the control group, ${ }^{\text {"P }}<0.05$ vs. the $\mathrm{H} / \mathrm{R}$ group, ${ }^{\prime \prime} \mathrm{P}<0.05$ vs. the curculigoside-treated group. MPTP, mitochondrial permeability transition pore; H/R, hypoxia/reoxygenation; Cur, curculigoside; ATR, atractyloside.

Curculigoside inhibits myocardial cell apoptosis and decreases the expression of cytochrome c, APAF-1, caspase-9 and caspase-3 at the gene and protein levels ex vivo. TUNEL staining revealed that myocardial apoptosis following $\mathrm{I} / \mathrm{R}$ injury was significantly decreased by pre-treatment with curculigoside (Fig. 7). RT-qPCR analysis revealed that I/R injury significantly upregulated the mRNA expression of cytochrome $c$, APAF-1, caspase-9 and caspase-3 compared with the control group ex vivo. Furthermore, curculigoside pre-treatment significantly attenuated the increased mRNA expression of the aforementioned proteins ex vivo (Fig. 8A). Additionally, western blot analysis revealed that the expression of these proteins in the I/R group was significantly upregulated compared with the control group. Curculigoside treatment prior to I/R injury significantly decreased the upregulated protein expression of cytochrome $c$, APAF-1, cleaved caspase-9 and cleaved caspase-3 (Fig. 8B).

Atractyloside abrogates the cardioprotective effects of curculigoside following $I / R$ or $H / R$ injury. In order to investigate whether curculigoside exerts cardioprotective effects following $\mathrm{I} / \mathrm{R}$ or H/R injury by inhibiting the opening of the MPTP, the effects of atractyloside, a known MPTP opener, were examined. Apoptosis was significantly increased in the myocardium ex vivo and in $\mathrm{H} 9 \mathrm{c} 2$ cells in vitro in the combination treatment group compared with the curculigoside-treated group (Figs. 2B and 7). Furthermore, the effects of the combination treatment on mitochondrial-mediated apoptosis were investigated. The cardioprotective effects of curculigoside following $\mathrm{I} / \mathrm{R}$ or $\mathrm{H} / \mathrm{R}$ injury were attenuated by atractyloside, and this 

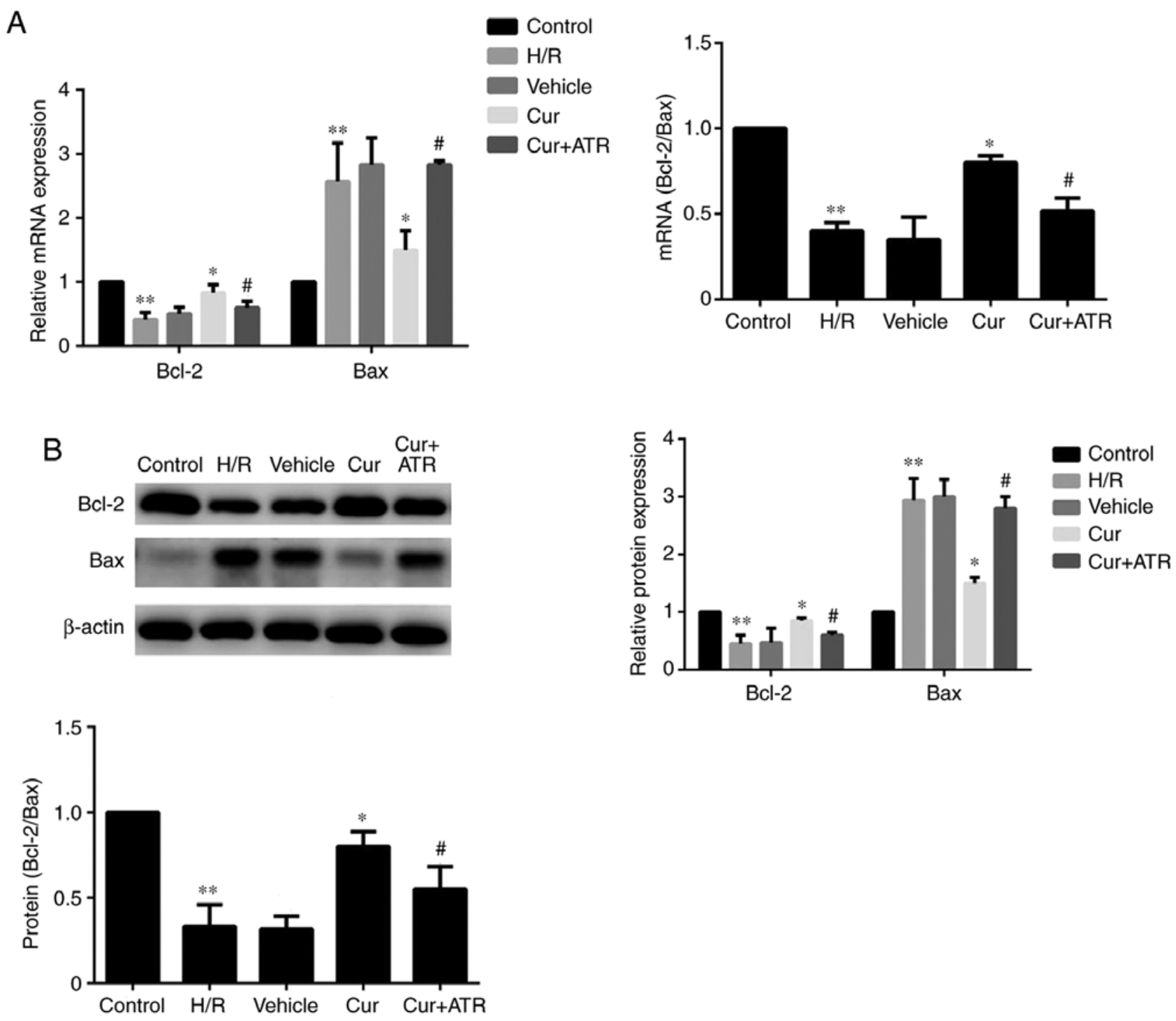

Figure 5. Curculigoside regulates the expression of $\mathrm{Bax}$ and $\mathrm{Bcl}-2$ at the gene and protein levels. (A) The mRNA expression of Bax and Bcl-2 was measured by reverse transcription-quantitative PCR. (B) The protein expression of Bax and Bcl-2 was analyzed by western blot analysis. ${ }^{* *} \mathrm{P}<0.05$ vs. the control group, ${ }^{\text {"P }}<0.05$ vs. the $\mathrm{H} / \mathrm{R}$ group, ${ }^{\mathrm{H}} \mathrm{P}<0.05$ vs. the curculigoside-treated group. Bcl-2, B-cell lymphoma 2; Bax, Bcl-2-associated $\mathrm{X}$ protein; H/R, hypoxia/reoxygenation; Cur, curculigoside; ATR, atractyloside.

resulted in decreased $\Delta \Psi \mathrm{m}$, the upregulated expression of cytochrome $c$, APAF-1, cleaved caspase-9 and cleaved caspase-3, increased MPTP opening, the decreased expression of Bcl-2 and the increased expression of Bax (Figs. 2A, 3A and B, 4, $5 \mathrm{~A}$ and $\mathrm{B}$, and $8 \mathrm{~A}$ and $\mathrm{B})$.

\section{Discussion}

MIRI occurs in a number of heart diseases, and while several therapeutic strategies have been proposed, there is currently no standard treatment protocol. Curculigo orchioides Gaertn is a traditional herb listed in Pharmacopeia of China (2015 edition) (27), which has been used to enhance kidney yang, strengthen bones and muscles, and alleviate coldness and wetness in the body in China for many centuries (28). A recent study also reported that the extracts from the rhizomes of the plant Curculigo orchioides Gaertnits exhibited potent antioxidant activities (29). Curculigoside is a major active constituent of Curculigo orchioides Gaertn and a number of previously published studies have revealed that curculigoside inhibits oxidative damage and $\mathrm{I} / \mathrm{R}$ injury in mouse cortical neurons, rat calvarial osteoblasts and human umbilical vein endothelial cells $(18,30,31)$. Thus, it was hypothesized that curculigoside may exert protective effects against MIRI. As expected, the results of the present study demonstrated that curculigoside attenuated MIRI in a dose-dependent manner in vitro and ex vivo. To the best of the authors' knowledge, the present study was the first to reveal the cardioprotective effects of curculigoside on MIRI. These findings suggest that curculigoside may have a potential use for the prevention of MIRI.

Curculigoside has been demonstrated to exhibit a protective effect in nerve tissue following oxidative stress by inhibiting mitochondria-mediated apoptosis (32). Furthermore, mitochondrial-mediated apoptosis has previously been implicated in MIRI $(33,34)$. Mounting evidence has demonstrated that MPTP plays an important role in modulating the mitochondrial apoptotic pathway, as MPTP opening releases 
A
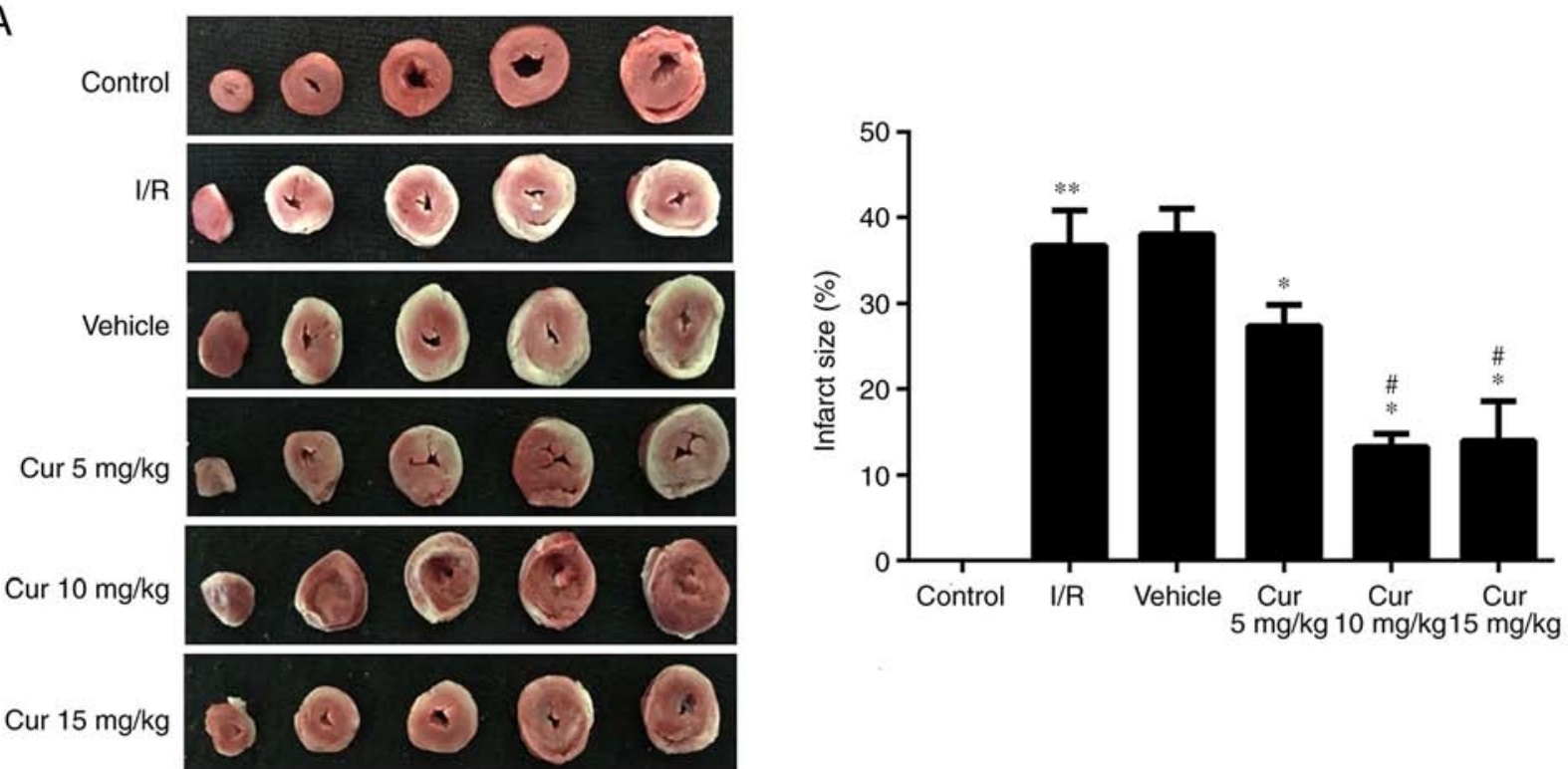

B

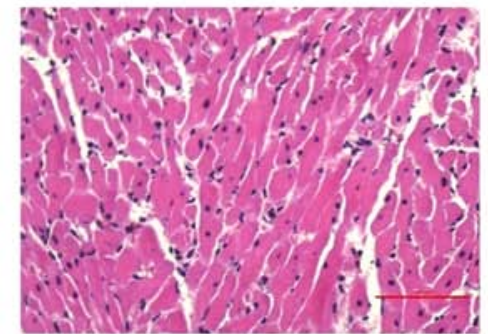

Control

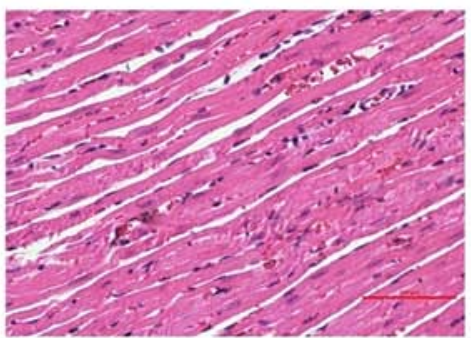

Cur $5 \mathrm{mg} / \mathrm{kg}$

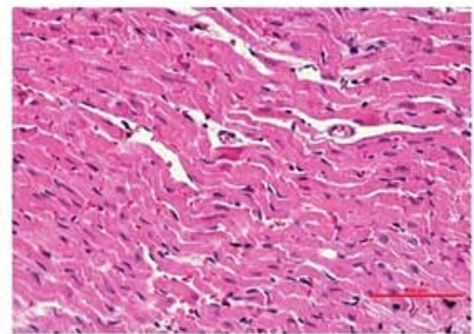

I/R

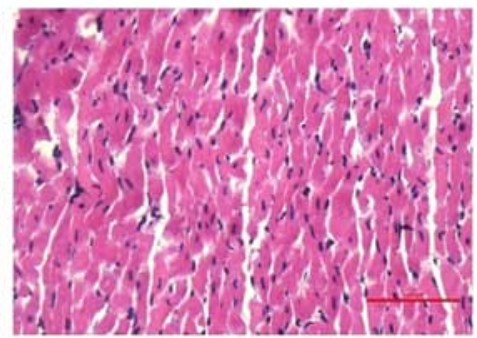

Cur $10 \mathrm{mg} / \mathrm{kg}$

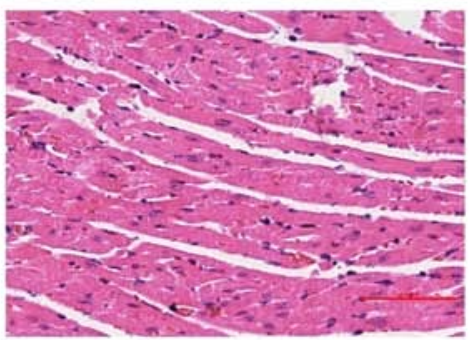

Vehicle

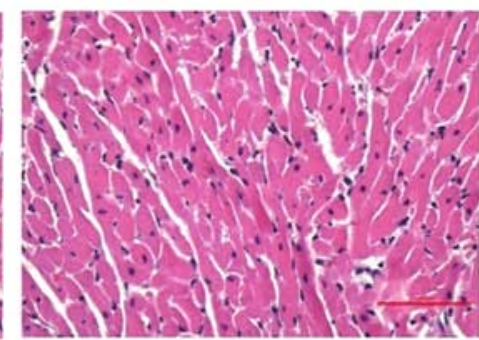

Cur $15 \mathrm{mg} / \mathrm{kg}$

Figure 6. Effect of curculigoside on I/R injury ex vivo. (A) Myocardial infarct size was evaluated by triphenyltetrazolium chloride staining. (B) The pathological characteristics in the myocardium were assessed by H\&E staining. $n=5-6$ per group. ${ }^{* *} \mathrm{P}<0.05$ vs. the control group, ${ }^{*} \mathrm{P}<0.05$ vs. the $\mathrm{I} / \mathrm{R}$ group, ${ }^{*} \mathrm{P}<0.05$ vs. the $5 \mathrm{mg} / \mathrm{kg}$ curculigoside-treated group. I/R, ischemia/reperfusion; Cur, curculigoside.

cytochrome $c$ and APAF-1, activates caspase-9 and caspase-3, and ultimately induces apoptosis $(35,36)$. A previous study revealed that MPTP opening played an important role during the course of cardiac I/R injury (37). Therefore, the present study investigated whether curculigoside exerted cardioprotective effects by inhibiting MPTP opening.

In the present study, the sensitivity of the MPTP to $\mathrm{Ca}^{2+}$ increased and $\Delta \Psi \mathrm{m}$ decreased in $\mathrm{H} 9 \mathrm{c} 2$ cells following $\mathrm{H} / \mathrm{R}$ injury. This resulted in MPTP opening, the increased expression of apoptosis-associated proteins and cardiomyocyte apoptosis (38). A decrease in $\Delta \Psi \mathrm{m}$ and an increased sensitivity of MPTP to $\mathrm{Ca}^{2+}$ are key features of mitochondrial-mediated apoptosis (39-41). In the present study, following curculigoside pre-treatment, the sensitivity of MPTP to $\mathrm{Ca}^{2+}$ and the loss in $\Delta \Psi \mathrm{m}$ were decreased, suggesting the inhibition of MPTP opening, and the expression of apoptosis-associated proteins and cardiomyocyte apoptosis were decreased. Atractyloside, a known MPTP opener, abrogated the inhibitory effects of curculigoside on the decreased expression of apoptosis-associated proteins and myocardial apoptosis. The results of the present study indicated that curculigoside targeted the MPTP and protected the rat myocardium and $\mathrm{H} 9 \mathrm{c} 2$ cells against I/R or $\mathrm{H} / \mathrm{R}$ injury by inhibiting MPTP opening.

Previous studies have revealed that Bax and Bcl-2 are key upstream proteins in the regulation of MPTP opening $(42,43)$. Bax binds to voltage dependent anion channels (VDAC) and leads to MPTP opening (44). However, Bcl-2 inhibits the binding of Bax to VDAC and p53 to peptidylprolyl isomerase D, 


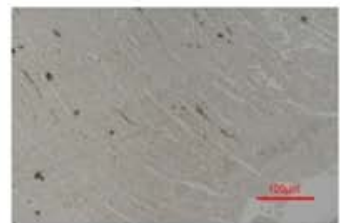

Control

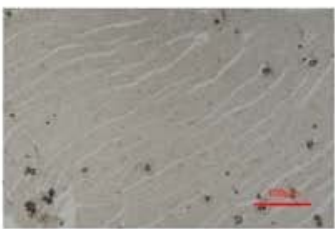

Cur

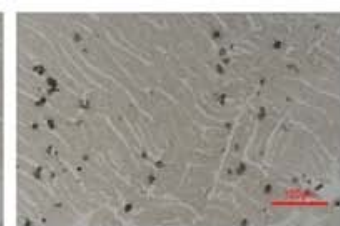

I/R

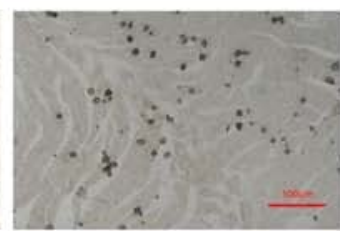

Cur+ATR

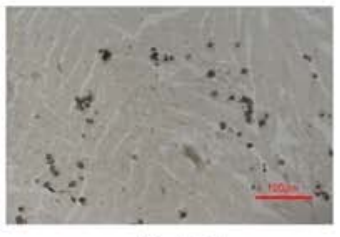

Vehicle

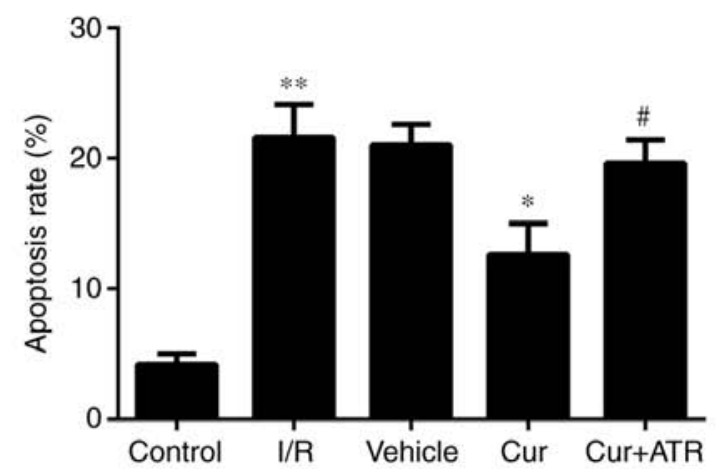

Figure 7. Curculigoside attenuates myocardial apoptosis ex vivo. Myocardial apoptosis was assessed by terminal deoxynucleotidyl-transferase-mediated dUTP nick-end labeling staining. $\mathrm{n}=6$ per group. ${ }^{* *} \mathrm{P}<0.05$ vs. the control group, ${ }^{*} \mathrm{P}<0.05$ vs. the $\mathrm{H} / \mathrm{R}$ group, ${ }^{\prime \prime} \mathrm{P}<0.05$ vs. the curculigoside-treated group. I/R, ischemia/reperfusion; Cur, curculigoside; ATR, atractyloside pretreatment group.

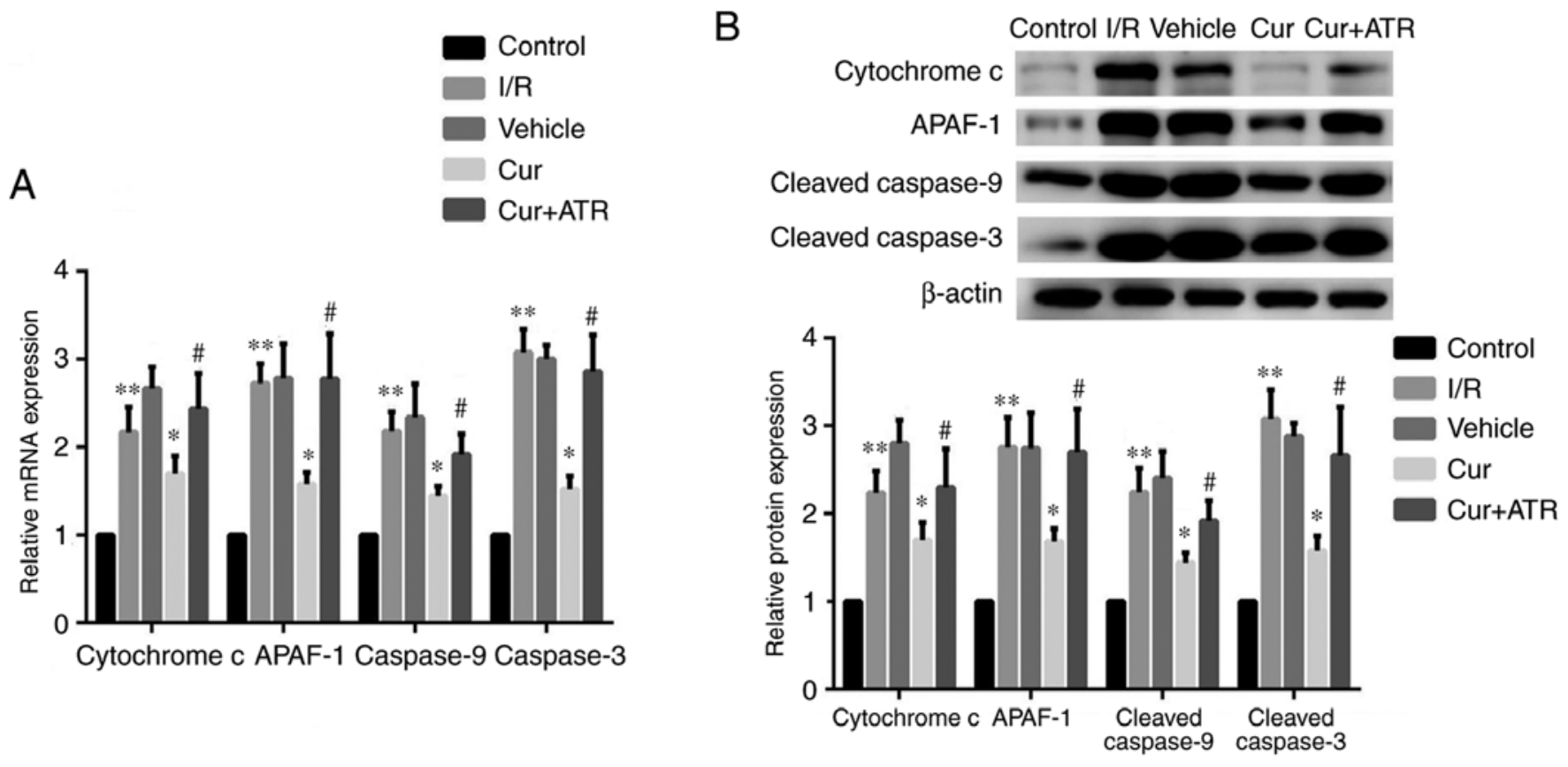

Figure 8. Curculigoside downregulates the protein expression of cytochrome $c$, APAF-1, caspase-9 and caspase-3 at the gene and protein levels ex vivo. (A) The mRNA expression of cytochrome $c$, APAF-1, caspase- 9 and caspase- 3 was evaluated by reverse-transcription quantitative PCR. (B) The protein expression of cytochrome $c$, APAF-1, cleaved caspase- 9 and cleaved caspase- 3 was examined by western blot analysis. $\mathrm{n}=6$. ${ }^{* * *} \mathrm{P}<0.05$ vs. the control group, ${ }^{*} \mathrm{P}<0.05$ vs. the $\mathrm{H} / \mathrm{R}$ group, ${ }^{\text {"P}} \mathrm{P}<0.05$ vs. the curculigoside-treated group. APAF-1, apoptotic protease activating factor-1; I/R, ischemia/reperfusion; Cur, curculigoside; ATR, atractyloside.

and decreases MPTP opening $(44,45)$. Therefore, the ratio of Bax/Bcl-2 regulates MPTP opening (46). The present study revealed that curculigoside increased the expression of Bcl-2, and decreased the expression of Bax, therefore increasing the Bcl-2/Bax ratio. This suggested that curculigoside inhibited MPTP opening by decreasing the $\mathrm{Bax} / \mathrm{Bcl}-2$ ratio.

The present study had two important limitations. Firstly, the isolated rat heart model lacks humoral and neural regulation and does not accurately represent the physiological progression of MIRI in situ. Future studies are required to investigate the cardioprotective effects of curculigoside in situ following I/R injury. Secondly, the present study demonstrated that curculigoside inhibited mitochondria-mediated apoptosis by acting on the MPTP. However, other apoptotic signaling pathways, such as death receptor-mediated apoptosis, were not investigated. Therefore, further investigation of the mechanism of action of curculigoside is required.

In conclusion, the present study revealed a previously unknown, at least to the best of our knowledge, cardioprotective effect of curculigoside. The results obtained in the present study may serve as the basis for the development of novel therapeutic agents for MIRI.

\section{Acknowledgements}

Not applicable. 


\section{Funding}

This study was supported by the National Natural Science Foundation of China (grant nos. 81670320 and 81800232) and the Natural Science Foundation of Liaoning Province (grant no. 201602826).

\section{Availability of data and materials}

The datasets generated and analyzed during the present study are available from the corresponding author on reasonable request.

\section{Authors' contributions}

DJ and NW conceived and designed the experiments. YZ conducted the experiments. YG, YC, and SL participated in the completion of the experiments. YZ and NW analyzed the data. $\mathrm{YZ}$ and $\mathrm{NW}$ wrote the manuscript. All authors read and approved the final version of this manuscript.

\section{Ethics approval and consent to participate}

The present study was approved by the Ethics Committee of China Medical University and procedures for animals handling and care adhered to the Guide for the Care and Use of Laboratory Animals.

\section{Patient consent for publication}

Not applicable.

\section{Competing interests}

The authors declare that they have no competing interests.

\section{References}

1. Writing Group Members, Mozaffarian D, Benjamin EJ, Go AS, Arnett DK, Blaha MJ, Cushman M, Das SR, de Ferranti S, Després JP, et al: Executive summary: Heart disease and stroke statistics-2016 update: A report from the American heart association. Circulation 133: 447-454, 2016.

2. Turer AT and Hill JA: Pathogenesis of myocardial ischemia-reperfusion injury and rationale for therapy. Am J Cardiol 106: 360-368, 2010.

3. Kalogeris T, Baines CP, Krenz M and Korthuis RJ: Cell biology of ischemia/reperfusion injury. Int Rev Cell Mol Biol 298 229-317, 2012.

4. Fraccarollo D, Galuppo P and Bauersachs J: Novel therapeutic approaches to post-infarction remodelling. Cardiovasc Res 94: 293-303, 2012.

5. Morciano G, Bonora M, Campo G, Aquila G, Rizzo P, Giorgi C, Wieckowski MR and Pinton P: Mechanistic role of mPTP in ischemia-reperfusion injury. Adv Exp Med Biol 982: 169-189, 2017.

6. Sanada S, Komuro I and Kitakaze M: Pathophysiology of myocardial reperfusion injury: Preconditioning, postconditioning, and translational aspects of protective measures. Am J Physiol Heart Circ Physiol 301: H1723-H1741, 2011.

7. Verma S, Fedak PW, Weisel RD, Butany J, Rao V, Maitland A, Li RK, Dhillon B and Yau TM: Fundamentals of reperfusion injury for the clinical cardiologist. Circulation 105: 2332-2336, 2002.

8. Nazari A, Sadr SS, Faghihi M, Azizi Y, Hosseini MJ, Mobarra N, Tavakoli A and Imani A: Vasopressin attenuates ischemia-reperfusion injury via reduction of oxidative stress and inhibition of mitochondrial permeability transition pore opening in rat hearts. Eur J Pharmacol 760: 96-102, 2015.
9. Murphy E and Steenbergen C: Mechanisms underlying acute protection from cardiac ischemia-reperfusion injury. Physiol Rev 88: 581-609, 2008.

10. Bernardi P and Di Lisa F: The mitochondrial permeability transition pore: Molecular nature and role as a target in cardioprotection. J Mol Cell Cardiol 78: 100-106, 2015.

11. Shires SE and Gustafsson $\AA$ B: Mitophagy and heart failure. J Mol Med (Berl) 93: 253-262, 2015.

12. Piot C, Croisille P, Staat P, Thibault H, Rioufol G, Mewton N, Elbelghiti R, Cung TT, Bonnefoy E, Angoulvant D, et al: Effect of cyclosporine on reperfusion injury in acute myocardial infarction. N Engl J Med 359: 473-481, 2008.

13. Morin D, Pires F, Plin C and Tillement JP: Role of the permeability transition pore in cytochrome $\mathrm{C}$ release from mitochondria during ischemia-reperfusion in rat liver. Biochem Pharmacol 68: 2065-2073, 2004.

14. Winkler HH, Bygrave FL and Lehninger AL: Characterization of the atractyloside-sensitive adenine nucleotide transport system in rat liver mitochondria. J Biol Chem 243: 20-28, 1968.

15. Murali VP and Kuttan G: Curculigoside augments cell-mediated immune responses in metastatic tumor-bearing animals. Immunopharmacol Immunotoxicol 38: 264-269, 2016.

16. Kubo M, Namba K, Nagamoto N, Nagao T, Nakanishi J, Uno H and Nishimura H: A new phenolic glucoside, curculigoside from rhizomes of Curculigo orchioides. Planta Med 47: 52-55, 1983.

17. Zhu FB, Wang JY, Zhang YL, Quan RF, Yue ZS, Zeng LR, Zheng WJ, Hou Q, Yan SG and Hu YG: Curculigoside regulates proliferation, differentiation, and pro-inflammatory cytokines levels in dexamethasone-induced rat calvarial osteoblasts. Int J Clin Exp Med 8: 12337-12346, 2015.

18. Wang YK, Hong YJ, Wei M, Wu Y, Huang ZQ, Chen RZ and Chen HZ: Curculigoside attenuates human umbilical vein endothelial cell injury induced by $\mathrm{H} 2 \mathrm{O} 2$. J Ethnopharmacol 132: 233-239, 2010.

19. Zhu H, He J, Ye L, Lin F, Hou J, Zhong Y and Jiang W: Mechanisms of angiogenesis in a curculigoside A-treated rat model of cerebral ischemia and reperfusion injury. Toxicol Appl Pharmacol 288: 313-321, 2015.

20. Jiang W, Fu F, Tian J, Zhu H and Hou J: Curculigoside A attenuates experimental cerebral ischemia injury in vitro and vivo. Neuroscience 192: 572-579, 2011.

21. Kang Z, Zhu H, Luan H, Han F and Jiang W: Curculigoside A induces angiogenesis through VCAM-1/Egr-3/CREB/VEGF signaling pathway. Neuroscience 267: 232-240, 2014.

22. Zhu H, Ding Y, Xu X, Li M, Fang Y, Gao B, Mao H, Tong G, Zhou L and Huang J: Prostaglandin E1 protects coronary microvascular function via the glycogen synthase kinase $3 \beta$-mitochondrial permeability transition pore pathway in rat hearts subjected to sodium laurate-induced coronary microembolization. Am J Transl Res 9: 2520-2534, 2017.

23. Kastenmayer RJ, Moore RM, Bright AL, Torres-Cruz R and Elkins WR: Select agent and toxin regulations: Beyond the eighth edition of the guide for the care and use of laboratory animals. J Am Assoc Lab Anim Sci 51: 333-338, 2012.

24. Wu N, Li W, Shu W and Jia D: Protective effect of picroside II on myocardial ischemia reperfusion injury in rats. Drug Des Devel Ther 8: 545-554, 2014.

25. Herr DJ, Aune SE and Menick DR: Induction and assessment of ischemia-reperfusion injury in langendorff-perfused rat hearts. J Vis Exp 27: e52908, 2015.

26. Livak KJ and Schmittgen TD: Analysis of relative gene expression data using real-time quantitative PCR and the 2(-Delta Delta C(T)) method. Methods 25: 402-408, 2001.

27. Chinese Pharmacopoeia Commission: Pharmacopoeia of the People Republic of China. Chin Med Sci Technol Press, Beijing, pp189-191, 2015.

28. Miao M, Tian S, Guo L, Bai M, Fang X and Liu S: The effect of curculigoside on mouse model of perimenopausal depression. Saudi J Biol Sci 24: 1894-1902, 2017.

29. Hejazi II, Khanam R, Mehdi SH, Bhat AR, Rizvi MMA, Thakur SC and Athar F: Antioxidative and anti-proliferative potential of Curculigo orchioides Gaertn in oxidative stress induced cytotoxicity: In vitro, ex vivo and in silico studies. Food Chem Toxicol 115: 244-259, 2018.

30. Tian Z, Yu W, Liu HB, Zhang N, Li XB, Zhao MG and Liu SB: Neuroprotective effects of curculigoside against NMDA-induced neuronal excitoxicity in vitro. Food Chem Toxicol 50: 4010-4015, 2012. 
31. Wang Y, Zhao L, Wang Y, Xu J, Nie Y, Guo Y, Tong Y, Qin L and Zhang Q: Curculigoside isolated from Curculigo orchioides prevents hydrogen peroxide-induced dysfunction and oxidative damage in calvarial osteoblasts. Acta Biochim Biophys Sin (Shanghai) 44: 431-441, 2012.

32. Changa HT, Jan CR and Liang WZ: Protective effects of a phenolic glycoside compound curculigoside on $\mathrm{h}_{2} \mathrm{O}_{2}$-induced oxidative stress and cytotoxicity in normal human breast epithelial cells. J Funct Food 41: 171-182, 2018.

33. Yang HX, Wang P, Wang NN, Li SD and Yang MH: Tongxinluo ameliorates myocardial ischemia-reperfusion injury mainly via activating parkin-mediated mitophagy and downregulating ubiquitin-proteasome system. Chin J Integr Med, Jun 21, 2019 (Epub ahead of print).

34. Li Y, Xiang Y, Zhang S, Wang Y, Yang J, Liu W and Xue F: Intramyocardial injection of thioredoxin 2-expressing lentivirus alleviates myocardial ischemia-reperfusion injury in rats. Am J Transl Res 9: 4428-4439, 2017.

35. Karch $\mathbf{J}$ and Molkentin JD: Identifying the components of the elusive mitochondrial permeability transition pore. Proc Natl Acad Sci USA 111: 10396-10397, 2014.

36. Baines CP, Song CX, Zheng YT, Wang GW, Zhang J, Wang OL, Guo Y, Bolli R, Cardwell EM and Ping P: Protein kinase cepsilon interacts with and inhibits the permeability transition pore in cardiac mitochondria. Circ Res 92: 873-880, 2003.

37. Xu Z, Alloush J, Beck E and Weisleder N: A murine model of myocardial ischemia-reperfusion injury through ligation of the left anterior descending artery. J Vis Exp 86: 51329, 2014.

38. Kim JS, Wang JH and Lemasters JJ: Mitochondrial permeability transition in rat hepatocytes after anoxia/reoxygenation: Role of $\mathrm{Ca}^{2+}$-dependent mitochondrial formation of reactive oxygen species. Am J Physiol Gastrointest Liver Physiol 302 G723-G731, 2012
39. Scarffe LA, Stevens DA, Dawson VL and Dawson TM: Parkin and pink1: Much more than mitophagy. Trends Neurosci 37: 315-324, 2014

40. Skulachev VP: Bioenergetic aspects of apoptosis, necrosis and mitoptosis. Apoptosis 11: 473-485, 2006.

41. Kim R, Emi M, Tanabe K, Murakami S, Uchida Y and Arihiro K: Regulation and interplay of apoptotic and non-apoptotic cell death. J Pathol 208: 319-326, 2006.

42. Low IC, Kang J and Pervaiz S: Bcl-2: A prime regulator of mitochondrial redox metabolism in cancer cells. Antioxid Redox Signal 15: 2975-2987, 2011.

43. Takahashi A, Masuda A, Sun M, Centonze VE and Herman B: Oxidative stress-induced apoptosis is associated with alterations in mitochondrial caspase activity and Bcl-2-dependent alterations in mitochondrial $\mathrm{pH}$ (pHm). Brain Res Bull 62: 497-504, 2004.

44. Martel C, Wang Z and Brenner C: Vdac phosphorylation, a lipid sensor influencing the cell fate. Mitochondrion 19: 69-77, 2014.

45. Green DR and Evan GI: A matter of life and death. Cancer Cell 1: 19-30, 2002.

46. Burguillos MA, Hajji N, Englund E, Persson A, Cenci AM, Machado A, Cano J, Joseph B and Venero JL: Apoptosis-inducing factor mediates dopaminergic cell death in response to LPS-induced inflammatory stimulus: Evidence in Parkinson's disease patients. Neurobiol Dis 41: 177-188, 2011.

This work is licensed under a Creative Commons Attribution-NonCommercial-NoDerivatives 4.0 International (CC BY-NC-ND 4.0) License. 